\title{
Depulsators before 0il \& Gas Field Plants and Equations for Calculating the Main Element of Depulsators, Venturi Nozzles
}

\section{Milshteyn LM* \\ Topenergomashprom Interbranch Scientific-Technical Complex, Russia}

*Corresponding author: Milshteyn LM, Topenergomashprom Interbranch Scientific-Technical Complex, (MNTK TEMP), Krasnodar, Russia, Tel: +7-918-44-66388; Email: mleonmark@gmail.com

\section{Review Article \\ Volume 3 Issue 6}

Received Date: October 31, 2019

Published Date: November 20, 2019

DOI: $10.23880 /$ ppej-16000208

\section{Abstract}

Pipe depulsators are preliminary gas separation devices (PGSD). Professor E.P. Zaporozhets, the author, developed alternative depulsators - Autonomous Venturi nozzles (AVN) and depulsators-distributors of flows (FDD) with a Venturi nozzle (VN) at the entrance. There is a new method of selecting depulsators of new generation on the basis of Venturi nozzle. This method allows selection of Venturi nozzle neck diameter that does not allow overflow of separators. The main size of Venturi nozzle is the diameter (reduced diameter) of the Venturi nozzle critical section. The article presents refined system of equations to determine VN geometric parameters and equation to calculate the area of Venturi nozzle critical section. Speed of liquid and gas in critical section should be no more than $20 \mathrm{~m} / \mathrm{sec}, 320 \mathrm{~m} / \mathrm{sec}$ respectively. AVN depulsators can be installed a few kilometres from the plant. AVN depulsators are more compact, PGSD are smaller in size, length and height. Depulsators of any type are installed before oil\&gas plants, mainly before inlet separators. Depulsators are installed in Western Siberia and Krasnodar region and are recommended at marine oil \& gas platforms.

Keywords: Depulsators; Oil \& gas; Venturi nozzle; Confuser; Diffusor

Review with Recommendations on Application and Calculations

At the output of the pipeline, that transport gas, oil and water to the oil \& gas plants for inhibition of liquid (watered down oil) the following depulsators are used in
Milshteyn LM [1]: preliminary gas separation device (PGSD), Figure 1, autonomous Venturi nozzles (AVN), Figure 2, flow distributing depulsators (FDD) with Venturi nozzle (VN) at the entrance, Figure 3. 


\section{Petroleum \& Petrochemical Engineering Journal}

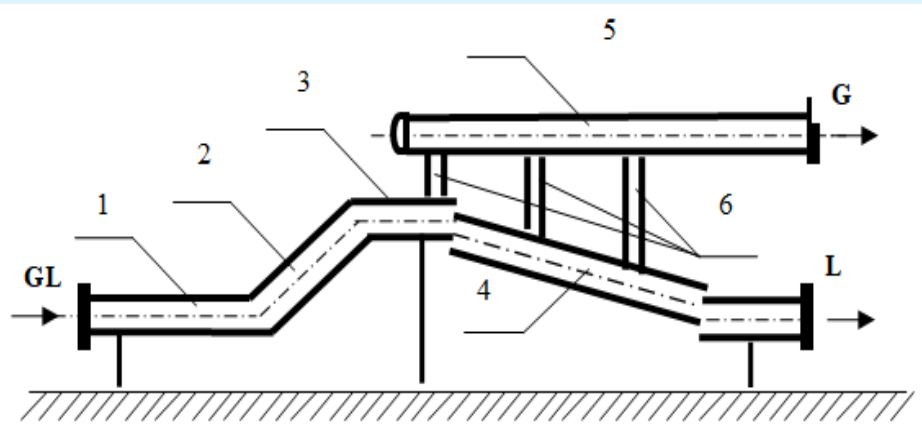

Figure 1: Preliminary gas separation device (PGSD): 1. Delivery of gas \& liquid mixture (GL); 2. Elevation of the mixture; 3. Depressant horizontal; 4. Descent of liquid (L); 5. Separated gas (G); 6. Vertical branch pipes connecting sections 4 and 5.

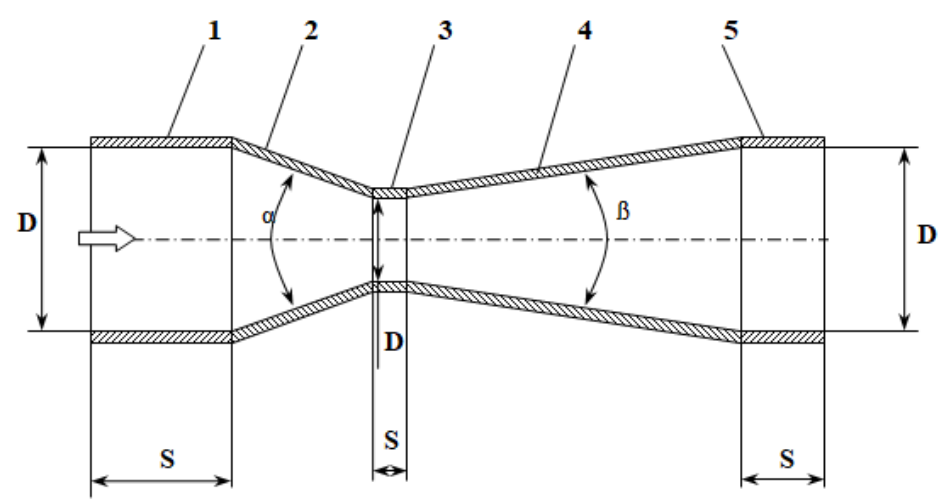

Figure 2: Venturi Nozzle (VN): 1. Entrance part before confusor; 2. Confusor; 3. Critical section (neck); 4. Diffusor; 5. Exit part after diffusor.

The geometric parameters of Venturi nozzle are determined by the system of equations [2]:

$D_{1} \approx D_{2}=(2.0 \ldots 3.0) D_{c} ; S_{1}=(1.0 \ldots 2.0) D_{1} ; S_{2}=(0.5 \ldots 1.0) D_{1} ; S_{K}=(0.05 \ldots 0.1) D_{c} ; \alpha,=20^{\circ} \ldots 45^{\circ} ;$

$\beta=5^{o} \ldots 10^{o} ; S_{c o n}=0,5\left(D_{1}-D_{c}\right) / \operatorname{ctg}^{\alpha} / 2 ; S_{d i f}=0,5\left(D_{2}-D_{c}\right) / c t g^{\beta} /{ }_{2} ; S_{\text {total }}=S_{1}+S_{c o n}+S_{c}+S_{d i f}+S_{2}$.

Diameters: entrance part to the nozzle confusor $\left(D_{1}\right)$, nozzle critical section $\left(D_{c}\right)$, the part after nozzle diffusor $\left(D_{2}\right)$;

Angles: narrowing of confusor $(\alpha)$, widening of diffusor ( $\beta$ );
Lengths: of the entrance part before confusor входного $\left(S_{1}\right)$, part after diffusor $\left(S_{2}\right)$, neck of the nozzle $\left(S_{c}\right)$, confusor $\left(\mathrm{S}_{\mathrm{con}}\right)$, diffusor $\left(\mathrm{S}_{\mathrm{dif}}\right)$, the total length of Venturi nozzle $\left(S_{\text {total }}\right)$. 


\section{Petroleum \& Petrochemical Engineering Journal}

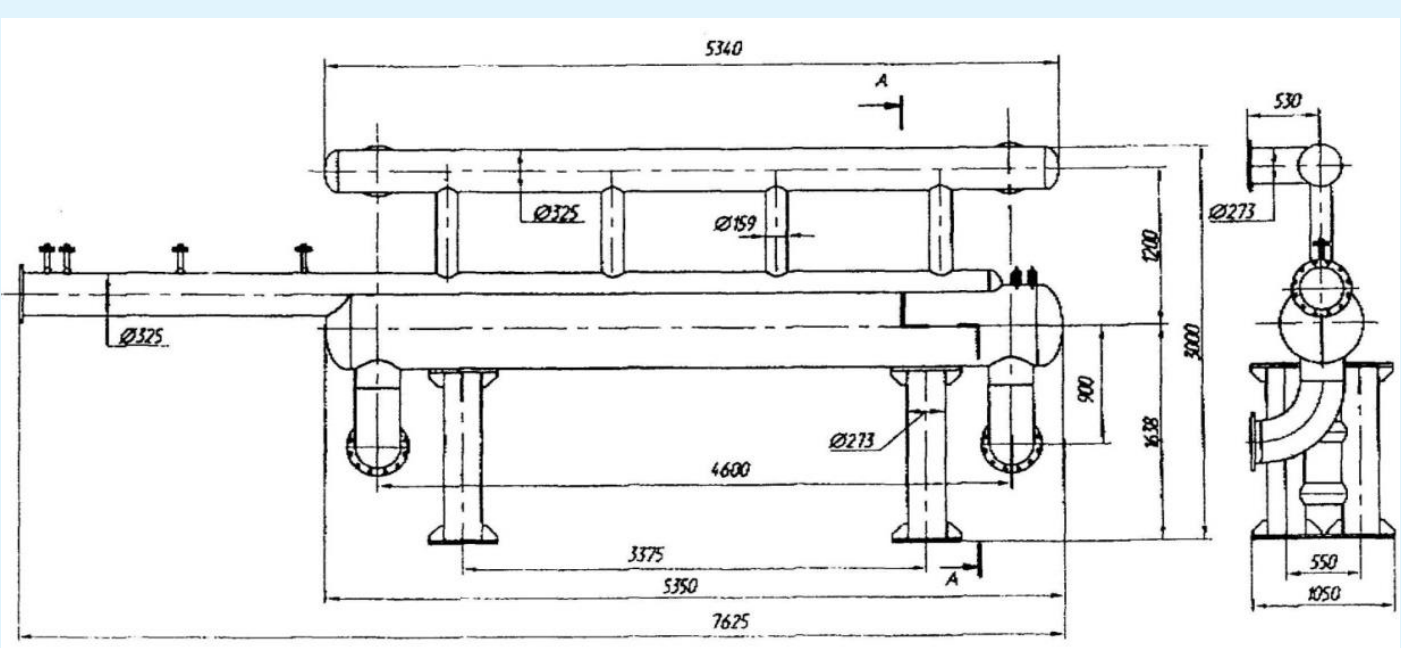

Figure 3: Design of flow destributing depulsator (FDD), installed before the two separators OGSW 1-0,6-2400 \{1\} of Khankovsky booster pump station (KBPS).

Important correlation for $\mathrm{VN}$ was Zaporozhets $\mathrm{EP}$, Milshteyn LM [3,4]: $D_{1}^{2} / D_{c}^{2}>2,0$ (1)

then replaced by Milshteyn LM, Zaporozhets EP, et al. [1,5]: $D_{1} / D_{c}>2,0$

Depulsators of all types are placed in front of oil \& gas plants, mainly in front of inlet separators. AVN can be installed in a few kilometers away from the plants. For example, depulsators ACV is located a few kilometers from Yuzhno-Balyk gas processing plant (YB GPP). AVN depulsators are installed before the entrance separators and heat exchangers, which are installed before them and have one branch pipe for the entry of mixture. PGSD and FDD depulsators are installed before the entrance separators with separate branch pipes for the entry of gas and liquid [1]. Depulsators of all types are installed before the following separators:

Oil\&gas separators (OGS) for separation of oil-gas mixture; Vertical three-phase separators (VTS) for separation of gasoil-solids mixture;

OGS with water discharge (OGSW) for separation of gas-oilwater mixture.

The area of critical section $\mathrm{VN}$ is determined by the formula [2]: $F_{c} \leq 0.2 F_{e l}$

(3), where $F_{c}, F_{\text {el }}$ is the area of VN critical section and throughpassage section of branch pipe or pipeline for the exit of liquid respectively, if the area of the last is less than that of the branch pipe.

The speed of oil gas through the VN neck should be less than the speed of sound of oil gases $W_{\mathrm{gsv}}=330 \ldots 430$ $\mathrm{m} / \mathrm{sec}$, otherwise the sound mode of the flow begins Milshteyn LM [1]. The Venturi nozzle has to be checked by the gas, so that the maximum allowed speed of gas in the neck $\left(\mathrm{W}_{\mathrm{gc}}\right)$ were less than the speed of sound $-\mathrm{W}_{\mathrm{gc}}=320$ $\mathrm{m} / \mathrm{sec}$. Estimated maximum speed of liquid in critical section of Venturi nozzle is $\mathrm{W}_{\mathrm{lc}}=20 \mathrm{~m} / \mathrm{sec}$.

The area of VN neck is limited by the expenditure of the liquid $\left(Q_{l}\right)[1,2]: F_{c} \geq Q_{l} / W_{l c}=0.05 Q_{l}(4)$, where $Q_{l}, W_{l c}$ is expenditure of the liquid, $\mathrm{m} / \mathrm{sec}$ and speed of liquid in the $\mathrm{VN}$ neck, $\mathrm{m}^{3} / \mathrm{sec}$, respectively.

Consider the work of Venturi nozzle in FDD depulsators of Slavyanski separation plant (SSP) and KBPS before the OGS and VTS oil \& gas separators respectively, Table 1 . There are two calculations of VN parameters: 1) with depulsators with Venturi nozzles according to relations (2); 2) with depulsators with VN, subject to formula (3) and (4). 


\section{Petroleum \& Petrochemical Engineering Journal}

\begin{tabular}{|c|c|c|}
\hline Parameters & FDD SSP and two OGS & FDD KBPS and two VTS \\
\hline Projected working pressure at the plant entrance, MPa abs. & 2.2 & 0.4 \\
\hline Capacity of two separators for liquid, $\mathrm{m}^{3} / \mathrm{sec}\left(\mathrm{m}^{3} / \mathrm{h}\right)$ & $0.05556(200)$ & $0.00833(30)$ \\
\hline \multicolumn{3}{|c|}{ Calculations 1, Parameters of Separators with FDD Equipped with VN According to Formula (1) or (2) } \\
\hline $\begin{array}{l}\text { The inner diameter of the inlet area into the nozzle confuser, } \\
\qquad \mathrm{D}_{1}, \mathrm{~mm}\end{array}$ & 309 & 75 \\
\hline Reduced diameter of Venturi nozzle critical section, $\mathrm{D}_{c}, \mathrm{~mm}$ & 142 & 30 \\
\hline Ratio (1), $\mathrm{D}_{1}^{2} / \mathrm{D}_{\mathrm{c}}^{2}\left((2), \mathrm{D}_{1} / \mathrm{D}_{\mathrm{c}}\right)$ and assessment of the equation & $4.7(2.2)>2.0$ & $6.3(2.5)>2.0$ \\
\hline Speed in exit branch pipes of liquid from separators, $\mathrm{m} / \mathrm{sec}$ & $9.0^{*}$ & 0.9 \\
\hline Relation of actual expenditure of liquid to critical expenditure & $2.2^{*}$ & 0.2 \\
\hline \multicolumn{3}{|c|}{ Calculations 2, Parameters of Separators with FDD Equipped with VN, Subject to Formula (3) and (4) } \\
\hline Selected diameter of Venturi nozzle critical section, $\mathrm{mm}$ & 80 & 40 \\
\hline Ratio (1), $\mathrm{D}_{1}^{2} / \mathrm{D}_{\mathrm{c}}^{2}\left((2), \mathrm{D}_{1} / \mathrm{D}_{\mathrm{c}}\right)$ and assessment of the equation & $14,9(3,9)>>2,0$ & $3,5(1,9)><2,0$ \\
\hline Speed of liquid in exit branch pipes from separators, $\mathrm{m} / \mathrm{sec}$ & 2.8 & 1.6 \\
\hline Relation of actual expenditure of liquid to critical expenditure & 0.7 & 0.4 \\
\hline
\end{tabular}

Table 1: Calculations of parameters for VN depulsators FDD SSP and FDD KBPS with two separators.

Note: * The parameters exceed maximum allowable

Venturi nozzle made according to the outdated formula (1) (calculation 1) leads to flooding of separators OGS with FDD (SSP), since the speed in exit branch pipes of liquid is more than the norm of $9 \mathrm{~m} / \mathrm{sec}>4 \mathrm{~m} / \mathrm{sec}$; and excess expenditure of liquid is above critical $-2.2>1.0$. Calculations 2 give examples of recommended selection of the diameter for the neck of Venturi nozzle, subject to formula (3) and (4), that does not allow flooding of separators, which cannot be guaranteed in PGSD.
Depulsators with VN, AVN and FDD, are calculated under the condition to prevent flooding of separators. Depulsator PGSD decreases accidents, but it does not prevent flooding of separators. PGSD of gas can be used only after confirming with the help of calculations that there is no flooding of separators. Table 2 compares different types of depulsators by size.

\begin{tabular}{|c|c|c|c|}
\hline Parameters of Depulsators & PGSD & FDD & AVN \\
\hline $\begin{array}{c}\text { Capacity: } \\
\text { by gas under the projected working pressure, } 0.4 \mathrm{MPa} \text { abs., } \mathrm{m}^{3} / \mathrm{h} \\
\text { by liquid, } \mathrm{m}^{3} / \mathrm{h}\end{array}$ & \multicolumn{3}{|c|}{$\begin{array}{c}29375 \\
96.7\end{array}$} \\
\hline Length of depulsator, m & 25 & 7.6 & 1.4 \\
\hline Height of depulsators from the ground level ("zero" point), m & 6.6 & 3.0 & 0.4 \\
\hline Size (volume) of depulsator, $\mathrm{m}^{3}$ & 115.5 & 23.9 & 0.2 \\
\hline Height of elevation of liquid over the supplying pipeline, $\mathrm{m}$ & 7.4 & 2.8 & 2.8 \\
\hline
\end{tabular}

Table 2: Size of depulsators installed before two OGSW plant KBPS.

Depulsator AVN is installed before YB GPP, Western Siberia, FDD is installed in Krasnodar region and both are recommended by the author for marine oil \& gas platforms [1].

\section{Conclusions}

1. There is a new method of selecting depulsators of new generation on the basis of Venturi nozzle, in particular, for the entrance oil \& gas separators OGS, VTS, OGSW, and heat exchangers installed before them. This method allows selection of Venturi nozzle neck diameter for AVN and FDD that does not allow overflow of separators. When using PGSD flooding cannot be avoided.

2. The main size of Venturi nozzle is the diameter (reduced diameter) of the Venturi nozzle critical section. The article presents refined system of equations to determine VN geometric parameters and equation to calculate the area of Venturi nozzle critical section. Speed of liquid and gas in critical section 


\section{Petroleum \& Petrochemical Engineering Journal}

should be no more than $20 \mathrm{~m} / \mathrm{sec}$ и $320 \mathrm{~m} / \mathrm{sec}$ respectively.

3. Depulsators of any type are installed before oil\&gas plants, mainly before inlet separators OGS, VTS, OGSW, where AVN can be installed a few kilometres from the plant. AVN depulsators are more compact, PGSD are smaller in size, length and height.

4. Depulsators AVN and FDD are installed in Western Siberia and Krasnodar region and are recommended at marine oil\&gas platforms.

\section{References}

1. Milshteyn LM (2017) Oil \& Gas Field Separation Technique. $2^{\text {nd }}(E d n),$.$\quad Open Science Publishing,$ Raleigh, North Carolina, USA, pp: 211.

2. Milshteyn LM (2018) Determination of Venturi Nozzles Dimensions of Pulsation Bottles Installed in front of Input Oil and Gas Separators. Equipment and Technologies for Oil and Gas Complex 2: 39-43.

3. Zaporozhets EP (2009) Principal patterns and methods of calculations for equipment and devices for gathering of large quantities of liquid from gas pipelines. UK Russ Gas Engineering, pp: 71.

4. Milshteyn L (2012) Modernization of oil and gas field separation. In: Lambert L (Ed.), Development of separation equipment and devices of new generation. Academic Publishing, Saarbrucken, Deuschland, pp: 124.

5. Zaporozhets EP, Antoniadi DG, Zibert GK (2012) Regular processes and equipment in technologies of collection, preparation and processing of oil and natural gases. Kuban state technological university, Krasnodar: Publishing house, pp: 620. 